Denken und zu einer erschöpfenden Erfassung strafprozessualer Tatbestände $z u$ erziehen, sondern daß sie darüber hinaus für ihn auch eine wirksame Hilfe bei der Examensvorbereitung bedeuten.

Aber auch dem in der Praxis stehenden Juristen wird das Buch eine willkommene Gelegenheit bieten, sich an Hand des ausführlichen Sach- und Gesetzesregisters über $Z$ weifelsfragen, die im täglichen Berufsleben auftreten, rasch und zuverlässig zu unterrichten.

Den das materielle Strafrecht behandelnden Band I „Praktische Strafrechtsfälle mit Lösungen" hoffe ich noch im Laufe dieses Jahres in Neuauflage folgen lassen zu können.

Heidelberg, Februar 1948

Dr. Petters

\title{
Vorwort zur sechsten Auflage
}

Der Neuauflage des Bandes 2 meiner „Praktischen Fälle mit Lösungen" liegen die neue Strafprozeßordnung und das neue Gerichtsverfassungsgesetz vom 12. September 1950 zugrunde. Der Umfang des Buches wurde infolge weiteren Ausbaues der ,Fälle“ und der ,Lösungen" und der mit ihnen jeweils in innerem Zusammenhang stehenden theoretischen Erörterungen (die diesmal äußerlich vollkommen von den eigentlichen Lösungen getrennt wurden) etwa um die Hälfte gegenüber der 5. Auflage vergrößert.

Die Neuauflage dient der Verwirklichung des gleichen Zieles, das auch mit den Strafrechtsfällen (Band 1 des Gesamtwerkes) angestrebt wurde, nämlich durch Kombination einer Fallsammlung mit einem Lehr-und Erläuterungsbuch in erster Linie dem juristischen $\mathrm{Nach} w \mathrm{uchs}$ ein Hilfsmittel für die Examensvorbereitung an die Hand zu geben. Darüber hinaus können aber die auf der Rechtsprechung des ehemaligen Reichsgerichts und auf grundlegenden Entscheidungen der Oberlandesgerichte einschließlich derjenigen aus den Jahren 1946-1950 aufgebauten ,Lösungen" a uch für den Praktiker von Nutzen sein, vor allem wenn es gilt, sich über $Z$ weifelsfragen, wie sie gerade auf dem Gebiete des Strafprozesses in der täglichen Praxis immer wiederkehren, Klarheit zu verschaffen; zu diesem $Z$ wecke stehen ein ausführliches Geset zesregister sowie ein alphabetisches Sachregister zur Verfügung.

In einer Kritik zu der Ende 1949 erschienenen 9. Auflage der Strafrechtsfälle wurde von berufener Seite (siehe Juristische Rundschau 1950 Heft 1) u. a. geäuBert, daß für einen Referendar, der in den strafrechtlichen Ausbildungsabschnitten dieses Buch durcharbeite, das große Staatsexamen auf einem wichtigen Prüfungsgebiet seine Schrecken verloren habe. Möge dieses Urteil in gleichem Maße auch für den vorliegenden prozessualen Parallelband in seiner neuen, erweiterten und verbesserten Auflage zutreffen.

Heidelberg, Januar 1951

Dr. Petters 